\title{
INNOVATIONS IN EDUCATION
}

\section{Peer Assessment of Professionalism: A Five-Year Experience in Medical Clerkship}

\author{
Regina A. Kovach, MD, David S. Resch, MD, and Steven J. Verhulst, PhD \\ Southern Illinois University School of Medicine, Springfield, IL, USA.
}

INTRODUCTION: Faculty assessment of students' professionalism is often based upon sporadic exposure to students. Peers are in a unique position to provide valid judgments of these behaviors.

AIMS: (1) To learn if peer assessments of professional conduct correlate with traditional performance measures; (2) to determine if peer assessments of professionalism influence the designation of honors, and (3) to explore student and faculty opinions regarding peer assessment.

SETTING: Internal Medicine Clerkship at Southern Illinois University.

PROGRAM DESCRIPTION: Since 2001 anonymous student peer assessments of professionalism have been used in assigning clerkship grades.

PROGRAM EVALUATION: Peer assessments of professionalism had weak, though significant, correlations with faculty ratings $(r=0.29)$, performance on the NBME subject test $(\mathrm{r}=0.28)$, and performance on a cumulative performance assessment $(r=0.30)$, and did not change the total number of honors awarded. A majority of students (71\%) felt comfortable evaluating their peers, and $77 \%$ would keep the peer evaluation procedure in place. A majority of faculty $(83 \%)$ indicated that peer assessments added valuable information.

DISCUSSION: Peer assessments of professional conduct have little correlation with other performance measures, are more likely to have a positive influence on final clerkship grades, and have little impact on awarding honors.

KEY WORDS: peer assessment; professionalism; undergraduate medical education.

J Gen Intern Med 24(6):742-6

DOI: $10.1007 / \mathrm{s} 11606-009-0961-5$

(c) Society of General Internal Medicine 2009

\section{INTRODUCTION}

Assessment of students' professionalism is difficult to do well. ${ }^{1,2}$ Peers, who interact with each other frequently and observe behaviors to which faculty are not privy, are in a unique position to provide valid judgments of behavior. ${ }^{1-5}$ Peer assessments allow teachers to benefit from additional perspec-

Received June 20, 2008

Revised January 21, 2009

Accepted March 12, 2009

Published online April 24, 2009 tives and have been recommended as a reliable method of professional assessment. ${ }^{5}$ Surprisingly, there are few successful peer assessment systems in place in US medical schools, and it is rare that peer assessments count toward summative grades. Many of the extant programs request learners to report on a limited number of peers (either randomly selected or self selected). ${ }^{6}$ Trainees often dislike and resist peer evaluations, stating that they hinder team relationships, promote competitiveness, and may cause harm by leading to an unfavorable grade. ${ }^{7-9}$ Students generally agree that a peer assessment system should: (1) be $100 \%$ anonymous, (2) provide immediate feedback, (3) focus on both unprofessional and professional behaviors, and (4) be used formatively to reward exemplary behavior and address repetitive professional lapses. ${ }^{3}$

There is limited published information on the use of peer assessments as part of a formal, summative evaluation in medical schools. At Southern Illinois University School of Medicine, use of peer assessments of professional behavior in determining final grades in the internal medicine clerkship has been in place since 2001 .

The objectives of this study are to: (1) learn if peer assessments of professional conduct correlate with other performance measures, (2) determine if peer assessments of professionalism influence the assignment of clerkship honors, and (3) explore student and faculty opinions regarding peer assessment.

\section{SETTING}

Southern Illinois University School of Medicine is a communitybased medical school with 72 students per class. Students participate in clinical clerkships during their third year, after participating for 2 years in a small-group, problem-based learning (PBL) curriculum. At the end of each PBL group, students provide verbal formative self and peer evaluations. ${ }^{10}$ In the medicine clerkship (http://www.siumed.edu/medicine/clerkship/index. $\mathrm{htm}$ ) students interact with their peers, residents, and faculty on specialty and general medicine services, as well as in groups during didactic conferences, standardized patient settings, and reports.

Student performance in all core clerkships is evaluated in three categories: (1) Clinical Performance, (2) Knowledge and Clinical Reasoning, and (3) Noncognitive Behaviors. The category of Noncognitive Behaviors addresses attributes associated with professional conduct, such as self-motivation, independent learning, interpersonal relationships, dependability, and integrity.

\section{PROGRAM DESCRIPTION}

A new evaluation system for the internal medicine clerkship was implemented beginning with the Class of 2001, in 
response to student feedback that the evaluation process should be more systematic and objective. A formula prioritizing several performance areas was developed by the clerkship director, then modified and approved by the medicine faculty after discussion. In the new system, each area-skills, knowledge, and noncognitive behaviors-contributes equally to the final clerkship grade. For each category, specific performance activities are assigned weights that determine the final grade (Table 1). Student peer assessment of professional attributes was formally included as one of the factors weighed in determining the final evaluation in the category of Noncognitive Behaviors. Peer evaluations account for 20 percent of the grade in the Noncognitive Behaviors category and 7 percent of the overall clerkship grade.

During orientation, the clerkship director explains the evaluation process, and students are told they will anonymously assess the professional behaviors of their peers at the conclusion of the clerkship. They are instructed to confine their assessments to noncognitive domains and advised to complete an evaluation of a peer only if they feel they have had sufficient interaction during the clerkship to form an accurate assessment. At the end of the clerkship, the clerkship administrator, whom students view as friendly and supportive, repeats these instructions and gives each student a folder containing separate evaluation forms for each peer in the clerkship. Students do not complete a self assessment.

The peer evaluation instrument (Appendix) has the identical items, descriptors, and 5-point rating scale as those on the form faculty have used for more than 20 years. The student form was not pilot tested.

To accomplish the study objectives, we conducted an analysis of existing performance records for the classes of 2001-2005 in which peer ratings of 349 internal medicine clerkship students were compared with clinical evaluations completed by faculty, NBME subject examinations scores, performance on a senior post-clerkship performance examination, and election at any time to the Alpha Omega Alpha Honor Society. In addition, senior students in the class of 2004 and the Internal Medicine Faculty voluntarily and anonymously completed author-generated opinion surveys about the peer assessment process. The student surveys were distributed and collected by a sophomore student volunteer during a single large group meeting; no faculty were present for the session. Faculty surveys were distributed by mail and collected by a research assistant.

This project received approval from the Southern Illinois University School of Medicine Springfield Committee for Research Involving Human Subjects.

Table 1. Clerkship Evaluation Scheme

\begin{tabular}{lll}
\hline \hline & $\begin{array}{l}\text { Category } \\
\text { weight }\end{array}$ & $\begin{array}{l}\text { Overall } \\
\text { contribution }\end{array}$ \\
\hline Clinical performance & & \\
$\quad$ Performance evaluations by faculty & $60 \%$ & $20 \%$ \\
Clinical skills exam (OSCE) & $25 \%$ & $8 \%$ \\
Chairman's presentation & $15 \%$ & $5 \%$ \\
Knowledge and clinical reasoning & & \\
NBME subject test & $60 \%$ & $20 \%$ \\
Clinical skills exam (OSCE) & $15 \%$ & $5 \%$ \\
Ambulatory care presentation & $15 \%$ & $5 \%$ \\
$\quad$ Performance evaluations by faculty & $10 \%$ & $3 \%$ \\
Professional and non-cognitive & & \\
behaviors & & $20 \%$ \\
Performance evaluations by faculty & $60 \%$ & $7 \%$ \\
Attendance & $20 \%$ & $\mathbf{7 \%}$ \\
Peer evaluation & $\mathbf{2 0} \%$ & \\
\hline
\end{tabular}

\section{PROGRAM EVALUATION}

We analyzed data collected from 349 students (100\% of students) over 5 years. Statistical analysis consisted of descriptive measures, correlations, paired t-tests, and analysis of variance, with statistical significance set at the five percent level. The reliability of the three-item peer evaluation tool was measured with Cronbach's alpha and found to be 0.89 , indicating strong internal consistency on a per student basis. An average of 18 students was in each clerkship, and we collected a mean of 12 anonymous peer evaluations per student (range 6-19).

Student assessments had mean peer ratings (4.18) that were lower than mean faculty ratings $(4.27, \mathrm{p}<0.001)$. Peer ratings of professional conduct had a weak correlation with faculty ratings $(r=0.29, p<0.001)$ (Figure 1). A weak, but statistically significant $(\mathrm{p}<0.001)$ correlation was also noted for the relationship between peer ratings of professional behaviors and performance on the NBME subject test $(r=0.28)$, faculty ratings of clinical skills $(r=$ $0.28)$, election to AOA $(r=0.24)$, and performance on a senior post-clerkship competency exam $(\mathrm{r}=0.30)$.

Students wrote over 1,800 comments on their peer evaluation forms. Using an iterative process, two authors (RK and DR) reviewed and categorized the comments into strengths $(1,545)$ and weaknesses $(316)$, subcategorized them into themes, and resolved any disagreement by consensus (Table 2). Themes addressing team communication, interpersonal interactions, and dedication to patients or educational events were most often spontaneously reported. There were often striking differences between faculty comments and peer comments about the same student that clearly illustrated a student's unique perspective (Table 3).

The results of the opinion surveys (Table 4) indicated that students and faculty felt the peer assessments added valuable information to evaluations, were equally or more accurate than faculty assessments, should continue as part of the evaluation process, and should remain anonymous.

Students and faculty wrote 181 comments that were categorized in a similar manner described for the evaluation tool (Table 5). The most common theme reflected concern about bias-driven remarks-either that friends would favor one another or that personality conflicts would interfere with honest reporting.

Overall, with peer assessments included, 32 students (9\%) received a better grade for the clerkship-an 'exceeds expectations' rather than 'satisfactory' rating in the category of Noncognitive Behaviors. Peer assessments accounted for honors for two students and the denial of honors for two students; however, the total number of honors awarded during the 5-year study period was unchanged. No student failed or remediated the clerkship because of peer assessments, but those with low ratings or troublesome comments received verbal feedback and counseling. Comparing the 5 years before to 5 years after the implementation of the new grading system, there was minimal impact on students who received 'exceeds expectations' for Noncognitive Behaviors (55\% before, 53\% after) or designation of honors (22\% before, $19 \%$ after).

\section{DISCUSSION}

The weak but significant correlation between peer and faculty evaluations of students' professional conduct supports the notion that students have a unique viewpoint that is valuable 


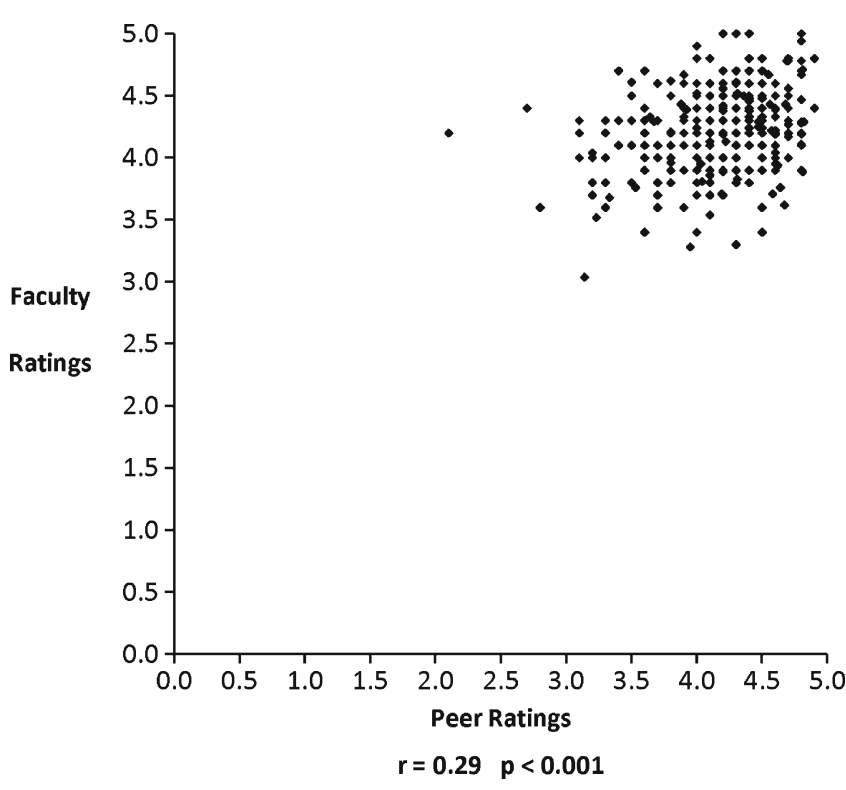

Figure 1. Correlations of peer ratings of professional conduct with faculty ratings (some data points overlap).

in assessment of noncognitive behaviors such as professionalism. Indeed, students are tougher graders than faculty, despite $41 \%$ saying they provided inflated ratings of their peers. Likewise, the lack of a strong relationship between peer assessments and traditional performance measures reinforces the belief that students contribute additional information, and can discriminate between their peers' academic performance and noncognitive attributes. These findings, along with the discordant faculty and student comments, are factors that speak to the value of peer assessments.

To our knowledge, there is only one other published report describing a core clerkship evaluation system where peer assessment of professional conduct is used for summative evaluation. ${ }^{2}$ Similar to our findings the authors found students could reliably evaluate their peers with a high degree of internal consistency. In contrast, they found that peer evaluations were an important reinforcer of faculty evaluations and were uncertain if peer evaluations offered a source of unique information.

Table 2. Content Analysis of Student Comments on Peer Evaluations

\begin{tabular}{lll}
\hline \hline & N & $\%$ \\
\hline Strength subcategories* & & \\
Work ethic/team skills & 424 & 27 \\
Dedication to patient care & 247 & 16 \\
Integrity & 157 & 10 \\
Motivation & 119 & 8 \\
Compassionate/caring & 55 & 4 \\
Non-specific (e.g., "great person") & 296 & 19 \\
Cognitive attributes (e.g., "very intelligent") & 247 & 16 \\
Weakness subcategories $\dagger$ & & \\
Inappropriate behavior/poor group skills & 90 & 28 \\
Tardiness/skipped required activities & 70 & 22 \\
Condescending attitude/arrogance/upstaging others & 53 & 17 \\
Lack of motivation & 34 & 11 \\
Lack of confidence & 25 & 8 \\
Dishonest & 20 & 6 \\
Non-specific (e.g., "unlikeable") & 24 & 8
\end{tabular}

*Number of comments classified as strengths: 1,545

$\dagger$ Number of comments classified as weaknesses: 316
Table 3. Examples of Peer and Faculty Comments of the Same Students Illustrating Differences

\begin{tabular}{lll}
\hline \hline & Peer evaluations & Faculty evaluations \\
\hline Student 'A' & Mean rating 2.7 & Mean rating 4.5 \\
& - Makes outrageous & - Always punctual \\
& inappropriate comments & and professional \\
- Lacks compassion & - Motivated, reliable \\
- Always managed to kiss & - Good work ethic, \\
- up to the attending & enthusiastic \\
& Always making excuses & - Dependable, \\
& compassionate \\
& - Did not cover his patients, & - Excellent rapport \\
did not do his share on & with patients \\
the wards & \\
- Constantly complains & - Personal style \\
about workload, patients, & with patients \\
faculty & occasionally \\
& paternalistic \\
- Thinks he's smarter than & \\
he is. Regularly late & \\
& \\
Mean rating 2.1 & Acts like he's above the & - Very dependable \\
rules & \\
- Not truthful with faculty & - On time, prepared \\
- Does as little as possible & - Good interpersonal \\
& skills; relates well \\
- A slacker; always late & - Very motivated \\
- Uses expletives on rounds; & - Has high level of \\
not respectful & interest \\
- Sucks up to residents who & - Could put forth \\
evaluate him & more effort \\
\hline
\end{tabular}

Peer assessment of professional behavior has been generally regarded as an appropriate formative, rather than summative, assessment method for medical students because it permits timely corrective feedback of problem behaviors and encouragement of a student's strengths. ${ }^{11,12}$ In contrast, there are questions about the reliability of summative peer assessments and their usefulness in high-stakes settings. ${ }^{13}$ Our experience indicates that the majority of faculty and students at our institution support student peer assessments as a meaningful contribution to the final clerkship grade. We believe that the anonymity of the evaluations favors acceptance, along with the

Table 4. Opinion Survey Results from Students and Faculty

\begin{tabular}{lll}
\hline \hline Survey item & $\begin{array}{l}\text { Student } \\
\text { survey N* (\%) }\end{array}$ & $\begin{array}{l}\text { Faculty } \\
\text { survey N* (\%) }\end{array}$ \\
\hline $\begin{array}{l}\text { Students felt comfortable } \\
\text { rating peers }\end{array}$ & $46(71)$ & N/A \\
$\begin{array}{l}\text { Peer assessments added valuable } \\
\text { information }\end{array}$ & $40(62)$ & $33(80)$ \\
$\begin{array}{l}\text { Students were influenced by } \\
\text { interactions prior to clerkship }\end{array}$ & $55(85)$ & $35(85)$ \\
$\begin{array}{l}\text { Peer assessments should be } \\
\text { anonymous }\end{array}$ & $49(75)$ & $34(83)$ \\
$\begin{array}{l}\text { Students provided inflated } \\
\text { assessments }\end{array}$ & $26(41)$ & $13(31)$ \\
$\begin{array}{l}\text { Peer assessments are more } \\
\text { accurate than faculty assessments }\end{array}$ & $27(41)$ & $14(33)$ \\
$\begin{array}{l}\text { Peer assessments are equally } \\
\text { accurate as faculty assessments }\end{array}$ & $44(22)$ & $14(33)$ \\
$\begin{array}{l}\text { Peer assessments should } \\
\text { be continued }\end{array}$ & $50(77)$ & $35(83)$ \\
\hline
\end{tabular}

Student survey response rate: 65/72, 90\%; faculty survey response rate: $41 / 55,75 \%$

$* \mathrm{~N}=$ Number of respondents agreeing with the item; not every respondent answered every item 
Table 5. Content Analysis of Comments on Student and Faculty Opinion Surveys

\begin{tabular}{|c|c|c|c|}
\hline Theme & $\begin{array}{l}\text { Student* } \\
\mathrm{N}(\%)\end{array}$ & $\begin{array}{l}\text { Faculty } \\
\text { N (\%) }\end{array}$ & Examples \\
\hline Bias influences ratings & $44(37)$ & $24(38)$ & $\begin{array}{l}\text { Students: "Some students can be spiteful" } \\
\text { "Friends rate friends well" } \\
\text { "As students, we have ulterior motives" } \\
\text { Faculty: "Peer assessments may represent a popularity contest" }\end{array}$ \\
\hline Anonymity of ratings & $10(8)$ & $10(16)$ & $\begin{array}{l}\text { Students: "I wouldn't have written anything negative if they weren't anonymous" } \\
\text { "Anonymous accusations should not be considered. They are not consistent with } \\
\text { our system of justice" } \\
\text { Faculty: "Because they are anonymous, students do not have to be accountable" } \\
\text { "Names may make them less open in their assessments" }\end{array}$ \\
\hline Unsupervised peer exposure & $9(8)$ & $7(11)$ & $\begin{array}{l}\text { Student: "As students, we see how each other behave at the rawest level" } \\
\text { Faculty: "Students are around each other all the time" }\end{array}$ \\
\hline Prefer formative evaluations & $7(6)$ & $0(0)$ & Student: "Use these $2 / 3$ way through for feedback, and don't count for grade" \\
\hline $\begin{array}{l}\text { Uncertain role of student } \\
\text { as professionals }\end{array}$ & $2(2)$ & $5(8)$ & $\begin{array}{l}\text { Student: "I'm not faculty and not experienced at assessing" } \\
\text { Faculty: "Students may have different expectations of what professional attributes are" } \\
\text { "Students are students; they are not yet professionals" }\end{array}$ \\
\hline $\begin{array}{l}\text { Needs administrative } \\
\text { interpretation of relevance }\end{array}$ & $0(0)$ & $8(13)$ & $\begin{array}{l}\text { Faculty: "Oversight by clerkship director is needed to assure comments are relevant } \\
\text { and valid" }\end{array}$ \\
\hline Non-specific & 46 (39) & $9(14)$ & $\begin{array}{l}\text { Student: "It was a good thing" } \\
\text { Faculty: "I like this system" }\end{array}$ \\
\hline
\end{tabular}

*All 65 students wrote comments for a total of 118 student comments

$\dagger$ Twenty-eight of 41 faculty (61\%) wrote comments for a total of 63 faculty comments

fact that the weighing of the peer evaluations is modest. Though not specifically explored on the surveys, it is possible the environment of our institution encourages acceptance of the process since students regularly complete global formative peer evaluations in the first 2 years of the curriculum. It may be that familiarity with the process, even when the stakes are higher, increases their comfort.

Some students and faculty expressed reasonable concerns about the system, and we share their worry about bias, unfair comments, and lack of accountability. The survey did not inquire if students rated their peers inappropriately low. These considerations, along with the written comments regarding negative bias, raise the possibility that deflated ratings were provided, although this is impossible to determine. The degree to which dishonesty and self interest influence peer ratings, as well as ways to safeguard students from unfounded comments and ratings, are areas for future investigation.

Despite these concerns, we believe that by recognizing and valuing student opinions in a process that counts, we demonstrated trust of their judgments and respect for them as professional colleagues. In addition, we feel the experience of being involved in a peer review process in school prepares them for similar obligations as residents and practicing physicians.

In summary, we feel the positive benefits of a summative peer assessment process are important, and the balance of weights we have designed is reasonable.

There are several limitations to this study. First, it was conducted at one medical school, and our findings may not generalize to other institutions. This may be especially true given the relatively small class size and cohesiveness of our school. Second, the first part of the study was an analysis of existing data, and third, only one class out of the five was surveyed. We found the survey data useful, but a larger sample size would have lent robustness to the results. In addition, talking to students in focus groups may have generated more insight into student opinion and should be considered as a supplemental procedure in the future. Last, though 11 evaluations have been suggested for reliable assessment of professional behavior, ${ }^{14}$ we did not manage students with fewer than 11 differently than those with more. We re-examined the 97 (28\%) students with fewer than 11 evaluations and found that peer evaluations affected the grades of seven: five (1\%) positively and two (1\%) negatively, with no change in the granting of honors.

\section{CONCLUSION}

We found that there was little correlation of peer assessments of professional conduct with other performance measures, and that students and faculty accepted peer assessments of professionalism as a meaningful contribution to their grade. Peer assessments are more likely to have a positive rather than a negative influence on the final clerkship grade and have little impact on the designation of honors. We believe they provide valuable information in the assessment of professional attributes of students and should continue to be used.

Acknowledgements: We thank Kate Beasley for her valuable help with data entry and manuscript preparation. There was no internal or external funding support for this study.

Conflict of Interest: None disclosed.

Corresponding Author: Regina A. Kovach, MD; Southern Illinois University School of Medicine, 701 N First Street-Room C402, PO Box 19636, Springfield, IL 62794-9636, USA (e-mail: rkovach@siumed. edu).

\section{REFERENCES}

1. Arnold L. Assessing professional behavior: yesterday, today, and tomorrow. Acad Med. 2002;77(6):502-15.

2. Arnold L, Willoughby L, Calkins V, Gammon L, Eberhart G. Use of peer evaluation in the assessment of medical students. J Med Educ. 1981;56(1):35-42.

3. Arnold L, Shue CK, Kalishman S, Prislin M, Pohl C, Pohl H, et al. Can there be a single system for peer assessment of professionalism among medical students? A multi-institutional study. Acad Med. 2007;82(6):578-86.

4. Cohen JJ. Measuring professionalism: listening to our students. Acad Med. 1999;74(9): 1010. 
5. Ramsey PG, Wenrich MD. Peer ratings. An assessment tool whose time has come. J Gen Intern Med. 1999;14(9):581-2.

6. Lurie SJ, Nofziger AC, Meldrum S, Mooney C, Epstein RM. Temporal and group-related trends in peer assessment amongst medical students. Med Educ. 2006;40(9):840-7.

7. Levine RE, Kelly PA, Karakoc T, Haidet P. Peer evaluation in a clinical clerkship: students' attitudes, experiences, and correlations with traditional assessments. Acad Psychiatry. 2007;31(1):19-24.

8. Rennie SC, Crosby JR. Students' perceptions of whistle blowing: implications for self-regulation. A questionnaire and focus group survey. Med Educ. 2002;36(2):173-9.
9. Van Rosendaal GM, Jennett PA. Comparing peer and faculty evaluations in an internal medicine residency. Acad Med. 1994;69(4):299-303.

10. Barrows HS. The Tutorial Process. Revised ed. Springfield, IL: Southern Illinois University School of Medicine; 1992.

11. Arnold L, Shue CK, Kritt B, Ginsburg S, Stern DT. Medical students' views on peer assessment of professionalism. J Gen Intern Med. 2005;20(9):819-24.

12. Epstein RM. Assessment in medical education. N Engl J Med. 2007;356 (4):387-96.

13. Norcini JJ. Peer assessment of competence. Med Educ. 2003;37(6):539-43.

14. Ramsey PG, Wenrich MD, Carline JD, Inui TS, Larson EB, LoGerfo JP. Use of peer ratings to evaluate physician performance. JAMA. 1993;269(13):1655-60.

\section{APPENDIX}

Student Peer Evaluation Rating Form

Southern Illinois University School of Medicine

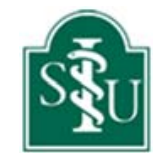

STUDENT PEER EVALUATION FORM

Student's Name:

Class Year:

Rotation:

KEY:

0 Unable to evaluate

1 Unsatisfactory

2 Marginal. Usually behaves professionally. Occasional lapses in behaviors that are below that expected of a medical student.

3 Meets expectations: The standard all professionals should be held to.

4 Commendable. Goes above what is expected.

5 Exceeds expectations. The kind of behavior all should strive for. Outstanding professionalism at all times.

\begin{tabular}{ccccccc} 
& UE & UNS & MAR & MEE & COM & EXC \\
& 0 & 1 & 2 & 3 & 4 & 5 \\
\hline \hline
\end{tabular}

SELF-DIRECTED LEARNING

Displays professional interest and curiosity; is dedicated and committed to work; is a self-motivated and independent learner; makes efficient use of time.

INTERPERSONAL RELATIONSHIPS

Cooperates and works efficiently with faculty, colleagues and other health professionals; is sensitive to and communicates well with patients/families.

\section{MOTIVATION/DEPENDABILITY/RESPONSIBILITY}

Conscientious and punctual in fulfilling clerkship responsibilities; displays initiative, diligence, and integrity; shows evidence of sound judgment as well as personal and professional maturity.

\section{COMMENTS:}

\section{Strengths}

